\title{
Tendencias epistemológicas en torno a la acción navegante del sujeto
}

\section{Epistemological tendencies around the subject's browsing action}

doi: http://dx.doi.org/10.32870/

José Guillermo Díaz Muñoz

espiral.v25i72.6999

\section{Resumen}

En el presente artículo se analiza el marco epistemológico actual desde el cual se opta explicar, comprender e interpretar los fenómenos sociales, particularmente desde la acción social transformadora del sujeto. Para ello, se hace un recorrido entre los principales pensadores de lo social más influyentes actualmente en las teorías de la acción, hasta terminar con algunas conclusiones desde la perspectiva latinoamericana. Se concluye que una cuestión central en el marco epistemológico analizado se refiere a la libertad de cada ser humano para actuar en la historia, y que esta cuestión atraviesa la historia del pensamiento y los estudios de lo social para dar cuenta de la discusión y tensión permanente entre la autonomía del sujeto y su determinación por la estructura social.

Palabras clave: epistemologías, pensamiento crítico, conocimiento, sujeto, incertidumbre.

\begin{abstract}
This article analyzes the actual epistemological frame from which several authors pretend to give an explanation, comprehension and interpretation of social phenomena, particularly since subject's action. So that we will realize a trip between the principal social thinkers who are actually influential in social action theories in order to conclude with some reflections since Latin American perspective. In this sense, a central item is referred to human being liberty and this approach is transversal to thinking history and social studies in order to clarify the permanent tension between individual autonomy and social structure determination.
\end{abstract}

Keywords: Epistemologies, critical thinking, knowledge, subject, uncertainty.

-Profesor-Investigador del Centro Interdisciplinario para la Formación y la Vinculación Social del Instituto Tecnológico y de Estudios Superiores de Occidente (ITESO), México. ORCID: http:// orcid.org/0000-0002-2092-7845_jguillermo@iteso.mx

Fecha de recepción: 07 de agosto de 2017. Fecha de aceptación: 13 de diciembre de 2017. 


\section{Introducción}

En el presente trabajo, se pretende analizar y comprender el marco epistemológico actual que se opta para explicar, comprender e interpretar los fenómenos sociales, particularmente desde la acción del sujeto. Una cuestión central en dicho marco se refiere a la libertad de cada ser humano para actuar en la historia, y esta cuestión atraviesa la historia del pensamiento y los estudios de lo social para dar cuenta de la discusión y tensión permanente entre la autonomía del sujeto y la determinación social a la que está sometido.

De ahí, se propone ejecutar un recorrido, llamándolo navegación, por algunos de los principales pensadores del cómo hacer conocimiento, rescatando algunos de sus aportes centrales a la epistemología, aunque desde la mirada de la acción. Algunas preguntas generales que orientan este recorrido son: ¿cómo definir al sujeto-agente-actor en su acción social transformadora?, ¿cuáles son las grandes propuestas epistémicas para la comprensión del mundo social?, y ¿bajo qué premisas se propone la construcción del conocimiento en torno a la acción social transformadora?

\section{Para situar el escenario: una mirada general a las teorías epistemológicas}

Entre las propuestas epistemológicas para el estudio y generación de conocimiento sobre lo social, podemos ubicar una serie de diferencias, tensiones y conflictos, siendo identificables como los principales las relaciones sujeto-objeto, individuo-sociedad, mente/razón-cuerpo, explicación-comprensión, estructura-agente, estructura-historia, formalismo-sociologismo, local-global, micro-macro, dentro-fuera, consensualismo-conflictivismo, entre otras.

Cómo se resuelven estas tensiones no dicotómicas, o cuáles son las principales apuestas epistemológicas, son 
materias de discusión permanente entre los científicos sociales. Sin embargo, si bien existe una enorme variedad de propuestas epistémicas para el conocimiento del conocimiento en las ciencias sociales (un pensar el pensamiento con el que pensamos), para fines analíticos podemos ubicarlas en diversas tendencias actuales.

La vertiente dominante, cuyo origen viene de las ciencias naturales del pensamiento newtoniano y cartesiano, está representada por el positivismo empirista y tiene como condición la exigencia de neutralidad científica, como postulado rector la búsqueda de la objetividad de los fenómenos sociales en cuanto hechos, y como fin la explicación de esos fenómenos sociales bajo un modelo explicativo (análisis) con cinco asunciones (Zolo, 2006):

- Explicación y previsión con base en leyes generales (desde regularidades observables, con su carácter causal o estadístico).

- Verificabilidad empírica y objetividad (conocimiento cierto y objetivo).

- Cuantificación y medición (técnicas cuantitativas).

- Sistematicidad y acumulatividad (lenguaje teórico estructurado y método inductivo riguroso).

- Avaloratividad (distinta de las valoraciones y prescripciones éticas o ideológicas).

El método fundamental de estas propuestas epistémicas es del tipo lógico o hipotético-deductivo: positivismo lógico vienés, combinado con operacionalismo (definición de conceptos, variables, indicadores e índices) y una medición pragmática. ${ }^{1}$

I. Hemos dejado de lado la comprensión propuesta por la sociología comprensiva, particularmente, aunque no sólo, de MaxWeber (1982).ParaWeber, la comprensión es la forma que adquiere la explicación del sentido de la acción social. Por tanto, explicar es comprender, mediante la metodología de la imputación causal o de los tipos ideales, las regularidades que determinan uno o varios comportamientos sociales. 
Como antítesis de estas epistemologías, se encuentra la corriente normativa y especulativa, de corte aristotélico y de tipo deductivo, cuyo método se centra en la reflexión subjetiva y no empírica de los fenómenos sociales. Se trata de un tipo de estudio de lo social cercano a la filosofía, un pensamiento sobre los fenómenos sociales que parte del deber ser de lo social, de la preminencia de los valores normativos sobre el tipo de sociedad que deberíamos ser en tanto aspiración humana.

La tercera propuesta epistemológica, que podría ser considerada como la vertiente del pensamiento crítico de la modernidad (posmodernidad), está representada por diversas escuelas o corrientes construidas en torno a la reflexividad, entre las que podemos ubicar las propias teorías de la reflexividad (con exponentes como Ulrich Beck, Anthony Giddens, Scott Lash y Pierre Bourdieu, entre otros).

Una propuesta que intenta superar las anteriores, y que las critica sin dejar de reconocer su valor, pero buscando una interpretación del mundo social vinculada a la acción, la constituye, como cuarta vertiente epistémica, el pensamiento complejo, donde la diversidad y la incertidumbre se vuelven reconocibles (con exponentes como Goran Thernborn, Edgar Morin y Pablo González Casanova, entre otros).

Finalmente, partiendo de la geopolítica, nuevas propuestas críticas a la modernidad se van configurando como alternativa epistemológica desde un lugar situado -tanto en América Latina como en el sur del mundo- en el reconocimiento de la colonialidad del saber eurocéntrico y, en contrapartida, por tanto, en la reivindicación de la diversidad de saberes.

Una vez realizada esta distinción entre algunos de los diversos paradigmas epistemológicos actuales, conviene reconocer sus aportes específicos desde el eje analítico que nos interesa: las teorías de la acción. 


\section{Acción reflexiva y complejidad como nuevas apuestas epistemológicas}

La reflexividad, como cuestionamiento crítico de la modernidad, apuesta por la recuperación del sujeto en los procesos de generación del conocimiento, tanto del investigador en su calidad de observador-conceptuador como del sujeto investigado, pero, al mismo tiempo, se propone también la apertura de fronteras de las ciencias sociales, en la búsqueda de una reunificación o articulación que permita obtener un conocimiento integrado de las realidades sociales.

Estas propuestas reflexivas, con sus más y sus menos, suponen nuevas miradas y rupturas epistemológicas con el paradigma dominante:

- Con la objetividad del método hipotético-deductivo, en tanto pasan de la mirada distanciada a una mirada implicada;

- Con las fronteras disciplinares, para entenderlas no como límite, sino como apertura;

- Con el conocimiento provisional, para pasar al conocimiento relativo;

- Con el conocimiento incuestionable, en defensa de otro cuestionable;

- Con la distancia y neutralidad objetiva, hacia la identidad como pertenencia y adscripción intersubjetiva, relacional y compleja (no dicotómica y recursiva).

En resumen, se puede afirmar que esta vertiente epistemológica reflexiva intenta romper con el método analítico cartesiano -como exclusivo para el logro de la objetividad científica en las ciencias sociales-, para poner el énfasis en el método hermenéutico interpretativo, pero además, esta corriente epistemológica busca reposicionar al sujeto como eje de la investigación e imaginación. No hay cultura ni sociedad ni ciencia sin sujeto, y viceversa. Así, a través de 
la reflexividad, se establece una relación o membrana rizomática entre el sujeto investigador y el sujeto investigado de doble rostro, una intersubjetividad reflexiva.

Esta reflexividad puede tener diversos matices según sus autores, pero estos confluyen en la necesidad de reincorporar al sujeto-observador con el sujeto de estudio. Para Bourdieu (Vázquez García, 2002), la reflexividad supone la objetivación del sujeto objetivante, dado que existen coacciones sociales que tienen la forma de obstáculos epistemológicos, en tanto son operadores políticos que contribuyen a reforzar los efectos de poder que se pretenden cuestionar. Así, el trabajo intelectual se entiende a la vez como un trabajo político, en donde la reflexividad crítica es necesaria porque la libertad y la autonomía no constituyen puntos de partida de la investigación. Es un ejercicio permanente, sin fin, de análisis de la imbricación histórica entre el conocimiento y el poder, entre el sentido y la fuerza.

Para otros pensadores, la reflexividad tiene diversos enfoques: Beck (1994), por ejemplo, la entiende desde la perspectiva política como modernización reflexiva ubicada en la sociedad del riesgo, la cual lleva, como consecuencia, a una política reflexiva, es decir, a un ejercicio de la subpolítica desde abajo o al margen de las instituciones políticas formales (desde la ciudadanía y los movimientos sociales apartidistas, y al margen de la lucha por el poder formal); para Giddens (1994), en cambio, la reflexividad tiene un fuerte énfasis cultural y se expresa en la sociedad reflexiva en el marco de la globalización y, por ello, se constituye en una sociedad global de carácter postradicional; Lash (1997), en contraposición con los anteriores, tiene su preocupación en el individualismo, de manera que para él la reflexividad se expresa en la comunidad reflexiva.

Sin embargo, es posible distinguir en los tres autores mencionados un hilo conductor: el referido a la sociedad occidental y su situación actual. Frente a esta posición 
eurocentrista, se manifiesta Therborn (2000), para quien, si bien actualmente en Europa se vive una etapa en los estudios sociales con una marcada tendencia en contra del estructuralismo y a favor de la reflexividad y la interpretación con base en el discurso, el futuro inmediato deberá dar paso a una epistemología basada en la globalización para la comprensión de los fenómenos sociales cuyos ejes epistémicos sean los actores en sistemas (con tensiones entre opciones-estrategias e inercia-resistencia), los sistemas autopoiéticos culturales y comunicacionales, y la relación entre las ciencias sociales (economía, ciencia política y sociología).

De ahí que la vertiente hermenéutica emergente reconozca también la división de las ciencias sociales, tanto en sus aportes al conocimiento como en sus implicaciones diversas (económicas, intelectuales y políticas). En ese sentido, se cuestionan sus alcances disciplinares y se proponen diversas alternativas para reunificar y abrir las fronteras, de manera que la realidad no sea abordada dicotómicamente (Bourdieu, Chamboredon y Passeron, 1976), en compartimientos estancos (Informe Gulbenkian, dirigido por Wallerstein -1996-), o como meramente legislativa (Bauman, 1997).

Así, la tendencia a la especialización en las ciencias sociales es múltiple (disciplinaria, subdisciplinaria, por áreas, por temas y por región), y tiene rasgos positivos (Morin, 2004), en tanto se vincula con la idea de progreso, acumulación de conocimiento y división del trabajo (las investigaciones empíricas se enfocan en aspectos específicos para enriquecer el análisis, lo que significa un valor positivo). Sin embargo, por otra parte, contiene también aspectos negativos: funciona en sentido inverso en universidades, centros, institutos de investigación y departamentos, es decir, con un movimiento de fragmentación que no atiende al mejoramiento del conocimiento sino a los intereses de grupos profesionales que disputan presupuestos y posiciones de 
autoridad en el campo intelectual. Este aspecto negativo de las ciencias sociales ha sido ampliamente analizado y cuestionado por Pierre Bourdieu bajo su concepto del homo academicus (Bourdieu, 2008; Vázquez García, 2002).

Este aporte al conocimiento por parte de las disciplinas es conceptualizado por Morin (2004) como la simplicidad, lo que establece una distinción fundamental con respecto a la complejidad. Desde la epistemología de la complejidad, Morin (2004) nos advierte que el principio de las ciencias clásicas es legislar, es decir, plantear leyes que gobiernan los elementos fundamentales de la materia o de la vida, y que, para ello, la ciencia debe desunir, reducir.

Estos principios siguen siendo válidos para Morin, pero insuficientes, dado que el método cartesiano como base del modelo científico contemporáneo va de lo complejo a lo simple, intentando leer la complejidad de lo real bajo la apariencia simple de los fenómenos. Por esta razón, el conocimiento puede tener un punto de partida, pero no un límite, punto de llegada o un término, sino que se constituye en una aventura en espiral y rizomática, realizada en círculos concéntricos.

Si bien se podría afirmar que las teorías de la complejidad tienen en Edgar Morin a un destacado referente, habría que añadir que Morin lo es desde la perspectiva epistémica del pensamiento complejo (con sus principios y método), mientras que muchos otros autores contribuyen al conocimiento de lo social desde otras perspectivas de la complejidad, como las ciencias de la complejidad, la perspectiva holista, los enfoques sistémicos, el paradigma ecológico y de la sustentabilidad, entre otras (Luengo, 2016).

De ahí la necesidad de realizar un esfuerzo de inter- y transdiciplinario por evitar la fragmentación del conocimiento. Para ello, se requiere la reflexión sobre el pensarhacer autónomo, en palabras de González Casanova (2004), un nosotros transcognitivo que vincule conocimiento, pala- 
bras y acción para alcanzar objetivos, o una realpolitik de la razón, a la manera de Bourdieu (Vázquez García, 2002), interviniendo para reducir la desigualdad de las condiciones materiales de existencia que excluyen el acceso efectivo a lo universal y estimulando material y simbólicamente los comportamientos que promuevan intereses universalizables (como el civismo, la solidaridad o la honestidad política y administrativa). Para Bourdieu, esta debe ser la función de los intelectuales en relación a una política de lo universal: actuar de manera coordinada y a escala mundial para garantizar la autonomía de los diferentes campos de producción cultural (científico, filosófico, artístico, etc.) con respecto a las intervenciones de otros campos (económico, político, periodístico, etc.) que actúan con cierta universalidad para imponer intereses particulares.

Esta es también la exigencia de la complejidad epistemológica: no existe fenómeno simple, sino que la realidad misma es compleja, es decir, irracional, con incertidumbre, con angustia y desorden. Así, la complejidad epistemológica reconoce los aportes de la simplicidad desde las ciencias, pero la trasciende. Incluso, si el conocimiento simplificante se funda en la fiabilidad absoluta de la lógica para establecer la verdad, para Morin el teorema de Gödel ha demostrado los límites de la demostración lógica en el seno de sistemas formalizados complejos, en la medida que el sistema sólo puede encontrar sus instrumentos en un sistema más rico o metasistema.

Los principios de la complejidad propuestos por Morin son los siguientes, en tanto reconocimiento de:

- Lo singular y local con la explicación universal;

- La organización y la desorganización de la realidad, el orden y el desorden, la dispersión y la constitución (tetragrama orden-desorden-interacciones-organización), de una manera dialéctica, contradictoria y complementaria; 
- La elementalidad-eventualidad y sistematicidad, es decir, las partes interactuando en el todo como sistema;

- La recursividad, en tanto retroacción entre causa y efecto (el producto es su propio productor, un bucle);

- La realidad como holograma, donde la parte contiene la información básica del todo, y el todo está presente en las partes (la célula-cuerpo o el individuo-cultura);

- La reflexividad, reintroducción del observador-conceptuador en la observación de la que forma parte, en un mundo social constituido por interacciones entre sujetos, finalmente en una sociedad formada por intersubjetividades.

Abonando también a esta perspectiva no dicotómica y compleja, para Bourdieu (2008; Vázquez García, 2002), en las ciencias sociales estamos habituados a pensar dicotómicamente: individuo/sociedad, mente/cuerpo, explicación/ comprensión, estructura/agente, sujeto/objeto, formalismo/ sociologismo, de manera que los obstáculos en el pensamiento científico provienen de ese trabajo en pares, que generan antinomias aparentes. Frente a estas antinomias, Bourdieu nos propone un pensamiento relacional, con nociones interconectadas como habitus, campo, espacio social, trayectoria social, capital o estrategia, pero, además, relacionar campos entre sí y sus interacciones (el campo de la economía con el campo de la política, por ejemplo).

Con su perspectiva, Bourdieu nos invita a elaborar un socioanálisis de la academia, al situar la génesis de esta conducta dicotómica dentro del habitus que rige la manera académica, escolástica, docta, de ver y vivir el mundo. Así, para Bourdieu, la forma objetivista de la investigación debe ser trascendida mediante una operación que objetive sociológicamente al investigador mismo. 


\section{Epistemología y dominación-acción}

Una perspectiva epistemológica adicional la constituye la tensión conflictiva entre la dominación (dominantes-dominados) y la resistencia-liberación de los dominados (sin que estas acciones dejen de ser recursivas). Entre los pensadores relevantes de esta perspectiva, queremos destacar a Pierre Bourdieu, Goran Therborn e Immanuel Wallerstein, así como a diversos pensadores latinoamericanos como Pablo González Casanova, Aníbal Quijano, Edgardo Lander, Alicia Montero, Gilberto Jiménez, y muchos más.

Una contribución particularmente importante de Bourdieu (Vázquez García, 2002) se refiere a la sociología de la acción o de la praxis (contra corrientes autonomistas o deterministas de la praxis), que frente a la fenomenología, ${ }^{2}$ reivindica la condición socialmente estructurada de la acción, mientras que frente al estructuralismo ${ }^{3}$ postula la condición radicalmente contingente e histórica de las estructuras.

Así, Bourdieu (Vázquez García, 2002) sostiene que las estructuras sociales poseen una existencia objetiva, bajo la forma de prácticas y modos de representación materializados históricamente en las instituciones y en las condiciones materiales de vida, pero también una existencia incorporada, bajo la forma del habitus como sistema de disposiciones adquiridas históricamente por los agentes en su relación con el mundo social.

Estas disposiciones operan activamente como principios de construcción del mundo social y están más allá de la oposición consciente/inconsciente (no motivos deliberados ni estructuras impensadas). Ellas existen en el cuerpo bajo la forma de

2. El sentido de la acción humana a través de la investigación de la experiencia vivida de los agentes, describiendo los contenidos intencionales de la conciencia que ellos proyectan en su acción y en la construcción interactiva del mundo social. 3. Ejecución de un sistema inconsciente de reglas que pueden ser analizadas científicamente por el investigador social. 
esquemas transferibles de producción y de representación de prácticas que permiten a los agentes apropiarse activamente de las instituciones en situaciones concretas.

La acción no es para Bourdieu (2008), por tanto, la ejecución automática de un sistema inconsciente de reglas ni el efecto mecánico de causas externas ni el resultado de un cálculo o de una decisión deliberada. Ella es producto de un sistema de disposiciones adquiridas por el cuerpo en su contacto continuo con las condiciones sociales de existencia. De ahí la necesidad de relacionar la ciencia social con la política y la ética desde una crítica social sin pretensiones, humilde y, por tanto, más potente, desenmascaradora de mecanismos de opresión y de la violencia simbólica. Este dominio se materializa en los campos, en tanto espacios de competición con reglas asumidas por los jugadores, pero con una competición mediada por una relación entre dominantes y dominados.

En esta perspectiva de la acción social, movilizadora y transformadora del sujeto, no podemos dejar de mencionar los valiosos aportes de Hugo Zemelman. En la conjunción de su enorme claridad y la densidad de su pensamiento, resulta conveniente recuperar su concepción del sujeto y de la construcción de la subjetividad, particularmente del sujeto social y la subjetividad social. Zemelman (2011) sostiene que esta doble perspectiva resulta problemática dado que el problema de los sujetos sociales no puede ser ajeno al conocimiento social, es decir, ninguna realidad social concreta puede entenderse sin el sujeto, o más precisamente, sin la presencia de algún tipo de sujeto. Además, estos sujetos lo son siempre en la medida en que se encuentran situados en redes o relaciones múltiples heterogéneas. En esta complejidad social, surge la enorme dificultad para comprenderlos, de manera que estos sujetos situados, ocupando espacios que implican reconocimiento a pertenencias colectivas, dan lugar a subjetividades sociales particulares 
y, en consecuencia, a sus particulares amplitudes espaciotemporales y sus densidades propias.

La subjetividad, por tanto, articula dimensiones micro- y macrosociales mediadas por la necesidad y experiencia del sujeto colectivo. Si bien las necesidades tienen su origen en la memoria y las tradiciones del sujeto, esta memoria se acompaña dialécticamente con su respectiva utopía o visiones sobre su futuro que se traducen en la capacidad del sujeto para construir proyectos y alternativas. Con todo, este proceso del sujeto puede estar condicionado por factores externos que se imponen sobre sus potencialidades autónomas, como las ideologías, impidiendo que el sujeto movilizado logre desplegar dichas potencialidades internas. Si ello acontece, Zemelman advierte que "su transformación en fuerza se hace con base en la construcción de un proyecto que es impuesto, sin que medie el desenvolvimiento de su capacidad para reconocer opciones y de reconocer su viabilidad" (2011, p. 359).

Sobre esta relación sujeto-conocimiento, Zemelman destaca que supone concebir la realidad como

[...] espacio donde se construyen sentidos, lo que obliga a incorporar el estar-siendo del sujeto, así como sus relaciones con otros. Es lo que obliga a comprender a los procesos sociales desde la recuperación de sus dinámicas gestantes, ocultas detrás de todas las formas establecidas y que se desplazan en diversos tiempos y espacios; dinámicas entre las que cabe destacar la necesidad de ser sujeto que, aunque callada, nos constituye (201 I, p. 362).

Por ello, en la medida en que las prácticas sociales crean realidades y a la vez son producto de procesos anteriores, para Zemelman (2006) la misma práctica social se transforma y trasciende a sí misma.

Por su parte, haciendo un esfuerzo por combinar la epistemología de la complejidad con una comprensión de la dominación para superar las limitaciones del pensamiento 
crítico, González Casanova (2004) nos advierte sobre la creencia -política, religiosa y científica- que lleva a pensar que existe un solo sistema (el capitalista), una política económica (el liberalismo), una política de Estado (la democracia de las élites) y una globalización (sustentada en el poder imperial). Estas son, para dicho sociólogo mexicano, las implicaciones políticas de la complejidad organizada, en la medida en que esta última provoca nuevas funciones y nuevas contradicciones en las relaciones de trabajo, en las relaciones coloniales y en las mediaciones mercantiles, sociales, políticas y culturales. Dicho de otra manera, el desarrollo tecnocientífico reestructura y contextualiza las relaciones de producción como relaciones de dominación de trabajadores y pueblos que no han podido comprender ni el pensamiento dominante ni el pensamiento crítico ni las fuerzas alternativas.

Esta complejidad obliga, entonces, a cambiar los comportamientos epistemológicos para definir y realizar lo no dado, lo emergente, donde el acto de juzgar sea sustituido por el acto de navegar y donde el acto de prever sea complementado con los de explorar, construir y luchar (la voluntad como conexión, representación, lucha y construcción). En síntesis, todo esto nos propone una particular epistemología de la acción desde la perspectiva del pensamiento complejo.

De esta manera, frente a un marxismo reduccionista y determinista - marcado por el modo de producción capitalista-, González Casanova (2004) nos invita a incluir en el centro del análisis los modos de dominación y los modos de mediación -complejos, organizados y estructurados- para redefinir las articulaciones, interfaces o enlaces que fundan lo subjetivo y lo objetivo en la creación histórica, que los unen, separan y contraponen en el conocimiento, la palabra y la acción. Por lo anterior, su crítica al pensamiento crítico estriba en la incapacidad de este de transcender la mirada sistémica, en la medida en que criticando al sistema domi- 
nante se trata de preservarlo con cambios fundacionales en los subsistemas dominantes y alternativos.

Siguiendo con González Casanova (2004), entonces, en su apuesta por una epistemología compleja y de la praxis, sólo el pensamiento antisistémico parece superar las alternativas clásicas de reforma o revolución y añadir a ellas los planteamientos que incluyen la construcción de fuerza y bloques desde la sociedad civil y las diferencias universales, hacia la configuración de otro sistema alternativo emergente, con capacidades de transformación ecológica, política, social, cultural, de mediación, de dominación, de apropiación, de producción en diversas escalas locales-universales, de subsistemas y sistemas alternativos, en formas continuas y discontinuas, directas e indirectas, entre bifurcaciones y opciones que no corresponden a un determinismo causal.

\section{Hacia una epistemología situada: una praxis desde la colonialidad y la diversidad del saber-hacer}

En el mismo sentido que González Casanova, y desde la perspectiva materialista de la geopolítica crítica, Lander (2000) y Quijano (2006) advierten que el paradigma positivista hoy dominante en las ciencias sociales tiene como origen la consolidación de las relaciones de producción capitalistas, y también el modo de vida liberal desde el cual estas últimas fueron adquiriendo el carácter de formas naturales.

Las ciencias sociales tienen como piso la derrota de las resistencias. A esta conclusión llega también la Comisión Gulbenkian en su informe, dado que las ciencias sociales se constituyeron como tales en un contexto espacial y temporal específico (Europa, segunda mitad del siglo XIX), separando la realidad en sus dimensiones económica, política y social para el estudio del presente a través de disciplinas respectivas: la sociología, la ciencia política y la economía. Al mismo tiempo, la antropología y los estudios clásicos se 
definen para los otros, y la historia para el pasado. Esta perspectiva eurocentrista se reexpresa actualmente, de acuerdo con Therborn (2000), en los pensadores críticos de la reflexividad.

Se trata entonces de una construcción eurocéntrica que organiza a la totalidad del tiempo y el espacio a partir de su propia experiencia, y que se constituye como patrón de referencia superior y universal en el que la sociedad industrial liberal se constituye a sí misma como la sociedad moderna y en el que lo otro es lo atrasado, lo arcaico, lo primitivo, en definitiva, lo premoderno, tanto en el ser como en su saber. Se trata, pues, del hecho de que las formas únicas, válidas, objetivas y universales de conocimiento para la comprensión de esa sociedad sean las occidentales. Estos saberes eurocéntricos han legitimado la misión civilizadora y normalizadora de occidente para todo el mundo, y una separación entre quienes tienen el saber y la verdad y quienes no la tienen.

En otros términos (Quijano, 2006), la producción de la modernidad y la racionalidad occidental es, de hecho, una expresión de la colonialidad del poder: dos caras de la misma moneda. Además, sus consecuencias para América Latina, a través de la dominación colonial, se suman a la racialización y a la reidentificación geocultural, con Europa Occidental como el centro de control del poder.

Esta colonialidad del poder ha producido, para Quijano (2006), el desencuentro entre nuestra experiencia histórica y nuestra perspectiva principal de conocimiento, y ha frustrado, en consecuencia, los intentos de solución eficaz de nuestros problemas fundamentales. De ahí los fantasmas históricos, problemas no resueltos, que pueblan nuestra región: identidad, democracia, unidad y desarrollo.

Dicho en palabras de Mignolo (2000, también citado por Walsh, 2003): la emergencia de la idea de hemisferio occidental ha dado lugar a un cambio radical en el imaginario y en las estructuras de poder del mundo moderno/colonial, 
y este imaginario del mundo moderno/colonial no es el mismo cuando se le mira desde la historia de las ideas en Europa que cuando se le mira desde la diferencia colonial (la colonialidad del poder en las Américas, Asia o África).

Dicho esto, existe una coincidencia entre diversos científicos sociales latinoamericanos que proponen el impulso de alternativas al pensamiento dominante eurocéntrico desde nuestra propia realidad. Los elementos de un paradigma latinoamericano de ver el mundo, de interpretarlo y actuar sobre él, son los siguientes (Montero, citada por Lander, 2000):

- Una episteme de relación con base en la comunidad, la participación y el saber popular;

- Liberación a través de la praxis, mediada por la conciencia crítica;

- El investigador social como actor social y constructor de conocimiento;

- El carácter histórico, indeterminado y relativo del conocimiento (multiplicidad de voces, de mundos de vida, la pluralidad epistémica);

- La perspectiva de la dependencia, la dominación, la colonialidad, la resistencia y la construcción de alternativas;

- La tensión hacer-conocer mediante la pluralidad de racionalidades y saberes.

Esta perspectiva latinoamericana de conocer nuestros problemas y no sólo los hechos de la realidad abreva de nuestra propia experiencia del pensar-saber-hacer, lo que implica a la investigación, la pedagogía y la acción. Abrevando de la filosofía de la acción y el pensamiento de Paulo Freire, González Casanova (2006) sugiere que el cambio entraña un nuevo sentido de la historia y de la política que encuentre y respete las simpatías y diferencias de una acción universal, en definitiva, una comprensión y acción alternativas y emergentes que busquen concebir-construir otro todo social. 


\section{Una sistematización de la acción desde diversas miradas epistemológicas}

Hemos hecho ya un breve repaso de los principales paradigmas epistemológicos y sus particulares abordajes a la acción de los sujetos, tanto del papel del investigadorconceptuador como del sujeto-objeto de investigación.

Conviene ahora intentar una aproximación cruzada de dichos paradigmas desde diversas miradas. Se trata de una sistematización inicial para contar con una visión de la acción desde la epistemología y las ciencias sociales y, por tanto, limitada en sus contenidos y alcances. Esta sistematización permite tener una perspectiva panorámica de las diversas corrientes en el sentido de la acción, pero es provisoria y tentativa, en la medida que podrían ser considerados nuevos aspectos relevantes y perspectivas.

Las diversas miradas son abordadas también a partir de sus principales características y tensiones desde los autores señalados en el inciso anterior, y sólo a través de ellos. Además, habrá que señalar que la separación de sus características es meramente artificial, dado que las diversas propuestas epistemológicas conllevan una articulación con énfasis diversos (tiempo-espacio-sujetos-estructura).

El esquema que se propone incluye las siguientes miradas de la acción, a partir de las tensiones y contradicciones principales a que está sometida en sus diversas dimensiones:

- Estructural: expresada por la relación agente-individuo/ estructura-sociedad y la tensión entre la autonomía radical del agente-individuo frente a la estructura social y la determinación del mismo por dicha estructura.

- Histórica: la tensión entre la existencia de un continuum de progreso histórico, expresado por premodernidadmodernidad-posmodernidad, y el reconocimiento de un sistema-mundo complejo de dominación y colonialidad, por tanto, y en el que existe una copresencia de ambos 
-del continuum referido de progreso histórico y del sistema-mundo complejo- en la diversidad cultural y territorial.

- Espacial: la tensión entre la concepción de un mundo como espacio globalizado y sin fronteras y la perspectiva epistemológica de reconocer las diferencias territoriales de la racionalidad y del saber.

- La cientificidad: la tensión entre la hiperespecialización de las ciencias necesaria para el progreso del conocimiento (disciplinar) y la necesidad de su reunificación para la comprensión de la realidad compleja (inter- y transdisciplinariedad), pero también la tensión entre los métodos lógico-deductivos (simplicidad) como aportes al conocimiento y el método hermenéutico interpretativo.

En torno a estas diversas tensiones, los autores analizados mantienen su propia posición. La Tabla 1 expresa esquemáticamente esas posiciones. 
Tabla 1. Corrientes epistemológicas y las teorías de la acción

\begin{tabular}{|c|c|c|c|}
\hline Dimensión & $\begin{array}{l}\text { Tensiones / } \\
\text { contradicciones }\end{array}$ & Contenidos & Perspectiva epistemológica \\
\hline \multirow[t]{3}{*}{$\begin{array}{l}\text { Estructural } \\
\text { Agente/ } \\
\text { estructura } \\
\text { Individuo/ } \\
\text { sociedad }\end{array}$} & $\begin{array}{l}\text { Autonomía del } \\
\text { agente }\end{array}$ & $\begin{array}{l}\text { Libertad de } \\
\text { elección, de } \\
\text { deconstrucción, } \\
\text { de producción de } \\
\text { sentido personal }\end{array}$ & $\begin{array}{l}\text { Racionalidad del sujeto } \\
\text { (rational choice) }\end{array}$ \\
\hline & $\begin{array}{l}\text { Determinación } \\
\text { por la estructura } \\
\text { social }\end{array}$ & $\begin{array}{l}\text { La estructura } \\
\text { social condiciona } \\
\text { al sujeto } \\
\text { (condiciones de } \\
\text { existencia) }\end{array}$ & Marxista, neomarxista \\
\hline & Codeterminación & $\begin{array}{l}\text { No dicotómicos: } \\
\text { autonomía } \\
\text { relativa del } \\
\text { sujeto frente a } \\
\text { la estructura } \\
\text { (conquista), } \\
\text { entendida la } \\
\text { segunda como } \\
\text { construcción social } \\
\text { y contingente }\end{array}$ & $\begin{array}{l}\text { Habitus: la acción mediada } \\
\text { por disposiciones adquiridas } \\
\text { en ciertos campos bajo } \\
\text { determinadas reglas } \\
\text { (Bourdieu). } \\
\text { Reflexividad: cuestionamiento } \\
\text { a la modernidad (Beck). } \\
\text { Recursividad-complejidad: el } \\
\text { productor es también su propio } \\
\text { producto (Morin). } \\
\text { Conciencia: la acción como } \\
\text { praxis liberadora a partir de la } \\
\text { conciencia (Quijano, Lander). } \\
\text { Actores en sistemas } \\
\text { (Therborn). } \\
\text { Sujeto-subjetividad social } \\
\text { (Zemelman). }\end{array}$ \\
\hline
\end{tabular}




$\begin{array}{lll}\text { Dimensión } & \begin{array}{l}\text { Tensiones/ } \\ \text { contradicciones }\end{array} & \text { Contenidos } \\ \text { Histórica } & \begin{array}{l}\text { Continuum } \\ \text { premodernidad- } \\ \text { modernidad- }\end{array} & \begin{array}{l}\text { Tendencia } \\ \text { histórica global: lo } \\ \text { poderno contra lo } \\ \end{array} \\ & & \begin{array}{l}\text { poscaico, primitivo, } \\ \text { premoderno }\end{array}\end{array}$

Copresencia de dichas realidades como: colonialidaddominación impuesta por Occidente (sistema-mundo moderno, economía-mundo capitalista)

Copresencia de
dichas realidades
como: dominación
desde la
complejidad

\section{Espacial \\ Espacio- territorio}

\section{Mundo} globalizado

$$
\begin{aligned}
& \text { Diversas } \\
& \text { realidades } \\
& \text { (globales, } \\
& \text { regionales, } \\
& \text { nacionales, } \\
& \text { locales) }
\end{aligned}
$$

No existencia de norte/sur, occidente/oriente y no sólo la
Perspectiva epistemológica

Eurocéntrica (Beck)
El todo organizadodesorganizado como lugar de la acción liberadora

Diversidad cultural e interculturalidad (Bauman). Luchas por la dominación desde los campos (Bourdieu). Diversas modernidades (Taylor-Flint).

Sistema-mundo con origen, desarrollo, crisis y transformación en la historia (Wallerstein).

Copresencia de diversas realidades (Quijano).

Saber-hacer como praxis de liberación (González Casanova)

Globalización como realidad compleja (Therborn)

El lugar importa (práctica y La praxis del sujeto desde el sur y la colonialidad (Quijano, acción situadas desde diversas racionalidades, occidental) 


\section{Dimensión Tensiones/ Contenidos Perspectiva epistemológica contradicciones \\ Cientificidad (Hiper)especia- Simplicidad El saber disciplinario aporta lización de las necesaria al conocimiento, pero este es ciencias sociales fragmentado (Morin)}

\begin{tabular}{|c|c|c|}
\hline $\begin{array}{l}\text { Reunificación } \\
\text { de las ciencias }\end{array}$ & $\begin{array}{l}\text { Romper con la } \\
\text { división artificial } \\
\text { de la realidad } \\
\text { social impuesta } \\
\text { por Occidente }\end{array}$ & $\begin{array}{l}\text { Contra los compartimientos } \\
\text { estancos del conocimiento } \\
\text { (Bourdieu, Wallerstein) }\end{array}$ \\
\hline & $\begin{array}{l}\text { La realidad } \\
\text { es compleja y } \\
\text { requiere la inter- } \\
\text { y transdisciplina } \\
\text { para trascender la } \\
\text { simplicidad }\end{array}$ & $\begin{array}{l}\text { Complejidad y sus principios } \\
\text { (Morin) }\end{array}$ \\
\hline $\begin{array}{l}\text { Método } \\
\text { hipotético- } \\
\text { deductivo }\end{array}$ & $\begin{array}{l}\text { Explicación } \\
\text { mediante causa- } \\
\text { efecto }\end{array}$ & $\begin{array}{l}\text { Simplicidad, estructuralismo } \\
\text { fenomenología }\end{array}$ \\
\hline
\end{tabular}

\begin{tabular}{|c|c|c|}
\hline \multirow[t]{2}{*}{$\begin{array}{l}\text { Método } \\
\text { interpretativo- } \\
\text { heurístico }\end{array}$} & $\begin{array}{l}\text { Objetivación del } \\
\text { sujeto objetivante; } \\
\text { introducción del } \\
\text { investigador- } \\
\text { conceptuador en } \\
\text { el proceso como } \\
\text { intersubjetividad; } \\
\text { principios de la } \\
\text { complejidad }\end{array}$ & Bourdieu, Morin, Zemelman \\
\hline & $\begin{array}{l}\text { Saber-hacer } \\
\text { (interpretación- } \\
\text { acción; } \\
\text { investigación- } \\
\text { praxis) }\end{array}$ & $\begin{array}{l}\text { El conocimiento como acción } \\
\text { liberadora y transformadora: } \\
\text { desde abajo y la colonialidad } \\
\text { (Quijano, Lander, González } \\
\text { Casanova) }\end{array}$ \\
\hline
\end{tabular}

Fuente: elaboración propia.

\section{0}


A manera de conclusión: la metáfora de la acción desde la perspectiva de la complejidad situada

Conforme a lo señalado al principio del presente trabajo, a través de la navegación realizada se propuso responder a dos grandes preguntas. Creemos que sus respuestas son todavía inciertas del todo, pero también que están más cerca de nuestro interés y comprensión.

El recorrido realizado partió del puerto de la simplicidad positivista y disciplinaria para avanzar más adelante por las aguas turbulentas de la incertidumbre y la complejidad, sin llegar todavía, porque el viaje, como el conocimiento mismo, es indefinido, indeterminado, sin límites, relativo, provisional.

Sin embargo, también habrá que decir que el puerto del que partimos está ubicado en Europa, por lo que durante un buen tramo del viaje fuimos acompañados por el pensamiento crítico eurocentrista, con sus distintos vientos, pero su impulso fue disminuyendo con la crítica situada desde la colonialidad y con la resistencia a la fuerza dominante de esos vientos.

Surgió, así, entre esas aguas turbulentas e inciertas de la complejidad, un viento fresco y nuevo, un viento reunificado, no escindido en flujos disciplinares y sociales separados, sino unido y potente, que nos puso en acción en ese mar global, ya no de propiedad europea y universal, sino diverso y plural, para navegar reconociendo que la dominación existe bajo formas nuevas, en las que el dominado colabora en su propia dominación, y que la tarea nos compete a todos los tripulantes -especialmente a los de abajo y a nuestras propuestas de emergencia- en el doble sentido del término: por su urgencia, por un lado, y por su acontecer como aparición prefigurativa de la acción transformadora del mundo, por otro. Una tarea que nos permite navegar en esas aguas complejas y diversas como saberes-haceres, 
comprensiones-acciones, racionalidades-actuaciones, impelidos por el viento unificado inter- y transdisciplinar, el cual es recogido (pero no atrapado, porque eso es imposible) por cada vela disciplinariamente, pero donde la unión de las velas-disciplinas en red y transversalmente forma también el velamen transdisciplinar.

Finalmente, comprendimos que el acto de navegar en la complejidad de las aguas es societario, que cada individuo y colectivo pone su parte, que sistémicamente nos movemos en la incertidumbre, y que requerimos concebirla como tal no sólo porque la realidad es así, sino para descubrir las mejores formas de transformarla -estrategias de apropiación, opciones de negociación y de resistencia- en ese saber-hacer rizomático y liberador para todos.

Bibliografía

Bauman, S. (1997). Legisladores e intérpretes: sobre la modernidad, la posmodernidad y los intelectuales. Argentina: Editorial Bernal.

Beck, U. (1994). "La reinvención de la política: hacia una teoría de la modernización reflexiva", en U. Beck, A. Gidden, y S. Lash. (Eds.), Modernización reflexiva. Política, tradición y estética en el orden social moderno (Pp. I3-72). Madrid:Alianza.

Bourdieu, P. (2008). Homo academicus. Buenos Aires: Siglo XXI Editores.

Bourdieu, P., Chamboredon, J. C., y Passeron, J. C. (I976). El oficio de sociólogo: presupuestos epistemológicos. México: Siglo XXI Editores.

Giddens, A. (1994). "Vivir en una sociedad postradicional”, en U. Beck, A. Giddens, y S. Lash. (Eds.), Modernización reflexiva. Política, tradición y estética en el orden social moderno (pp. 75-136). Madrid:Alianza.

González Casanova, P. (2004). Las nuevas ciencias y las humanidades. De la academia a la política. Barcelona: Antropos.

\section{2}


Lander, E. (2000). "Ciencias sociales: saberes coloniales y Bibliografía eurocéntricos", en E. Lander (Comp.), Colonialidad del saber. Eurocentrismo y ciencias sociales (Pp. I I-40). Buenos Aires: CLACSO-UNESCO.

Lash, S. (1997). Sociología del posmodernismo. Buenos Aires: Amorrortu.

Luengo, E. (2016). “Las vertientes de la complejidad. Diferencias y convergencias. Pensamiento sistémico, ciencias de la complejidad, pensamiento complejo, paradigma ecológico y enfoques holistas". Ponencia presentada en el Congreso mundial por el pensamiento complejo: los desafios en un mundo globalizado. UNESCO, París, Francia.

Mignolo,W.D. (2000).“'La colonialidad a lo largo y a lo ancho: el hemisferio occidental en el horizonte colonial de la modernidad", en W. Mignolo (Aut.), La colonialidad del saber: eurocentrismo y ciencias sociales. Perspectivas latinoamericanas (pp.55-85). Buenos Aires: CLACSO. Recuperado de: http://www.duke.edu/ wmignolo/Interactivecv/ Publications/Lacolonialidad.pdf

Morin, E. (2004).“'La epistemología de la complejidad”. Gazeta de Antropología, (20), I- I3. Recuperado de: http://www. ugr.es/ pwlac/G20_02Edgar_Morin.html

Quijano, A. (2006).“Don Quijote y los molinos de viento en América Latina”. Pasos (segunda época), ( 27), I-I4. Recuperado de: http://biblioteca.clacso.edu.ar/Costa_Rica/ dei/20 I 207 I I 0 I3853/donquijote.pdf

Therborn, G. (2000).“Ante el nacimiento de la segunda centuria de la sociología: tiempos de reflexividad, espacios de identidad y nudos del conocimiento". British Journal of Sociology, 5 I ( I ), 37-57.

Vázquez García, F. (2002). “La tensión infinita entre la historia y la razón: Foucault y Bourdieu”. Revue Internationale de Philosophie, (2), I07-I 22.

Wallerstein, I. (1996). Abrir las ciencias sociales. México: Siglo XXI. 
Bibliografía Walsh, C.(2003).“Las geopolíticas del conocimiento y colonialidad del poder. Entrevista a Walter Mignolo”. Polis, (4), I-22. Recuperado de: https://polis.revues.org/7/38 Weber, M. (1982). Ensayos de metodología sociológica. Sobre algunas categorías de la sociología comprensiva. Argentina: Amorrortu.

Zemelman, H. (2006). El conocimiento como desafio posible. México: Instituto Politécnico Nacional.

Zemelman, H. (20I I). "Sujeto y subjetividad: la problemática de las alternativas como construcción posible". Polis, 9(27), 355-366. Recuperado de: http://www.scielo.cl/ pdf/polis/v9n27/art 16.pdf

Zolo, D. (2006). “La tragedia de la ciencia política”. Metapolitica, (49), 49-6I. Recuperado de: http://www.metapolitica.com.mx/?method=display_articulo\&idarticulo= I 68\&idpublicacion $=1$ \&idnumero $=16$ 